\title{
Uses and Abuses of Geomagnetic Charts in Latin America
}

\author{
Luiz Muniz BARRETO \\ PAIGH Working Group on Geophysical Maps, Observatório Nacional, 20921 Rio de Janeiro, Brasil
}

(Received October 9, 1989; Revised April 16, 1990)

\begin{abstract}
A careful historical analysis of geomagnetic charts shows that their uses have changed between the fifteenth century and the present time. Their exclusive use for navigation has been expanded to a broad application spectrum that includes all orientation purposes and, more recently, prospecting activities and basic geomagnetic research. Such changes have necessitated considerable modifications in chart production, including more accurate data acquisition and analysis, besides the introduction of different methods of graphical representation, in order to express the geomagnetic main field or a local field including anomalies. An adequate choice of scales is essential to discriminate different kinds of field representation. As a consequence of a lack of coordinated work and the stage of scientific development, geomagnetic charts for Latin America do not present a desirable uniformity. For this season, the Pan-American Institute of Geography and History Working Group on Geophysical Maps is attempting to improve geomagnetic charts, through coordinated work on all parts of the subject.
\end{abstract}

1. Objectives and Uses of Magnetic Charts, from the Fifteenth Century to the Present Time

Three of four centuries ago, isogonic charts had a fundamental importance in maritime discoveries, since they were one of the few aids for defining the course of a vessel and for estimating longitudes in unknown ocean.

On the other hand, the uncertainty of such graphical representations, derived from inaccurate observational data and a crude knowledge of geomagnetic phenomena, was insufficient to solve the problems of the called "art of navigation".

For this reason, from a historical point of view, the lists of magnetic declination published by the Portuguese navigator Castro (CHAPMAN, 1967) and the magnetic charts for the South Atlantic produced by Edmond Halley (CHAPMAN, 1941) are very important documents.

For the South American continent, Halley's charts are the first accurate information, since other contemporaneous data are inconsistent or have been lost, and are useless for secular variation studies. Errors greater than two degrees for declination are common in magnetic observations made during colonial times.

Owing to the importance of the practical use of declination, isogonic charts became the most "popular" geomagnetic representation and for many users, they were confounded with a complete description of the geomagnetic field. Among inattentive users of those charts, such erroneous conception is persistent up to the present.

Little by little, magnetic charts became more accurate, permitting their use as a basic tool for surveying, aerial navigation and for general orientation questions. For this reason, a practical use in work on land has been added to their essential help in ocean 
adventures. For this reason, practical land applications of geomagnetic charts were expanded to become an essential part of ocean technology.

Some decades ago, the importance of magnetic charts as navigational aids was reduced by the introduction of modern methods of navigation (e.g. LORAN). Sophisticated methods of orientation and of estimating geographic coordinates changed the uses of magnetic charts from an essential one to one of simple point of reference.

However, other applications of magnetic charts have been created, resulting in a different approach to their production and methods of their applicability.

The growing importance of geophysical prospecting has involved changes in some aspects of magnetic charts making them very distinctly from the old "per mare currere" charts that were prevalent up to the nineteenth century.

Furthermore, the geographical distribution of geomagnetic field elements and their time variations became prominent factors in research with the Earth's structure. This new use has given a basic scientific importance to geomagnetic charts with more accurate requirements for their production, in addition to a global consideration of the geomagnetic field, requiring international collaboration.

A brief analysis of both new uses of geomagnetic charts, prospecting and in geomorphological and geophysical research, shows that the graphical representation used should have two different forms. Prospecting work needs a knowledge of crustal structure, mainly in its more superficial levels, and it involves relatively small areas of the planetary surface. Geomorphology and global geophysics must consider an object very similar to what Gilbert called the "Great Magnet" (CHAPMAN, 1967).

Generally speaking, a perfunctory description of this dual aspect of the question is the choice of appropriate scales for graphical representation. Such scales must be able to represent a local magnetic field or a normal magnetic field.

\section{Regional Magnetic Charts for Latin America}

The IGRF, International Geomagnetic Reference Field (IAGA, 1969; LANGEL, 1987), gives a global representation of the main geomagnetic field. Because of its planetary characteristics it is generally not suitable for geophysical prospecting and surveying users. Such users have regional needs and large scales are necessary to satisfy them.

Notwithstanding the fact that isolines must be denser than those of the IGRF representation, they must have a general pattern in accordance with the IGRF trend.

A very common question presented to regional chart makers is: what kind of geomagnetic field must be represented on their charts, main field or a local magnetic field?

Once again, this is a question of scale. A main field representation for a national or regional area could be meaningless, depending on the size of the area. A local magnetic field representation involves sources associated with magnetic material in the crust and includes those caused by induced electric currents.

In Latin America, where geomagnetism is a new science and there is a lack of coordinated work, a current misinterpretation of both kinds of charts is perceptible.

As a consequence of a tradition, not very old indeed, national and regional magnetic charts (including two or more small countries) are prepared from measured values of geomagnetic elements without any corrections for diurnal and seasonal variations or 
solar cycle effects. Connecting point with equal values of the elements, or using a crude graphical interpolation process in order to obtain round figures, isolines are traced.

If such a procedure is used after a reasonable application of corrections for the different variations, the charts produced should represent a draft of a local magnetic field, which includes the main field and some crustal anomalies and induced fields. However, account must be taken of the scale of the charts or, in other words, the size of coverage. If a large area is considered (for instance, something between $10^{5}$ to $10^{6} \mathrm{~km}^{2}$ ), large anomalies should be detectable, leaving medium or small ones indistinguishable, if we use a practical size for the charts. All those considerations are associated with a feasible number of observing stations.

The users of such charts must be informed about their characteristics, because the charts represent neither the main field nor a chart of anomalies.

Another common procedure is the use of a "magnetic baricentre" of three repeat station values. Such an easy method works as an arithmetic filter, rejecting local anomalies when their area is less than the dimensions of the triangle formed by the three stations. The choice of adequate repeat stations, and their distribution, are important steps in furnishing a reasonable network of "baricentres".

If variations corrections are applied to the observed values, and classical observing requirements are used, such a network of "baricentres" from a network of well-chosen repeat stations, free from anomalous disturbances, should give an acceptable set of values for regional or national geomagnetic charts, very close to a main-field representation.

However, Latin-American chart makers frequently use the crude process of tracing isolines without a mathematical adjustment of the data, in spite of recommendations from two regional meetings (GAMA, 1969a; BARRETO, 1984) and the explanations in Wienert's classical book (WIENERT, 1970).

GAMA (1969b) gives a detailed exposition of the use of a 2nd-degree polynomial for the Brazilian territory, which was followed by GoDOY (1970) and MOTTA and BARRETO (1986). A study of different polynomial degrees (BARRETO, 1987) shows that for the Brazilian area $\left(\simeq 8.5 \times 10^{6} \mathrm{~km}^{2}\right)$ a fourth-degree polynomial provides a very close approach to a main-field representation which follows the general pattern of the IGRF.

In order to develop geophysical modelling in Latin-American countries, the PanAmerican Institute of Geography and History, an organization sponsored by all American countries, linked to the American States Organization (RoDRIGUEZ, 1990), created in 1987 a Working Group on Geophysical Maps. The group is attempting the necessary systematization of measurement methods and data analysis through a cooperative programme involving all American countries, concentrating mainly with regard to the geomagnetic field.

An extensive work had been started in 1989, and the first results, based on the three points below, will be published early in 1991 .

a) A broad survey of old and recent measurements in Latin America is being made in order to organize a useful and informative record. Instruments and observing methods used will be described in order that error estimates may be made.

b) An effort to standardise the reoccupation of repeat stations and a general review of their distribution is being made, as well as an attempt to modernize instruments and methods.

c) Using recent and good quality repeat station measurements, a spherical cap harmonic model (HAINES, 1985) is being prepared for Brazil, based on a network of 105 
repeat stations scattered over a $8.5 \times 10^{6} \mathrm{~km}^{2}$ area.

\section{Abuses of Geomagnetic Charts}

In human activities it is very common to find a great optimism in the use of scientific data. This aspect is due to the actual development and power of science. Uninitiated people consider as absolute truth all measuring processes or mathematical analyses of natural phenomena.

However, a careful consideration of scientific information is imperative in order not to use a gun to kill a fly or a needle to kill an elephant.

Such simple mockeries could be applied to our charting problems. If we intend to produce magnetic charts for navigation purposes, a small scale is necessary, covering a large area, or in the case of global aeronautical charts. Using an appropriate scale for such a representation, local magnetic anomalies will not be present, and it is the main field that is considered. It is clear that we should expect errors of several minutes when using such charts.

An user of a 1:10 million scale chart cannot notice a $20 \mathrm{~km}$ anomaly, because the chart is a graphical representation of the main field or the so-called normal geomagnetic field (SCHMIDT, 1916; GAMA, 1969b).

On the other hand, a user of a 1:10000 chart cannot use it for secular variation studies.

Such incorrect applications are frequently caused by the chart makers, because they do not give sufficient information about the methods used to produce them or about the expected errors for a rational utilization of the charts.

\section{REFERENCES}

BArReto, L. M. (Ed.), Records of the Workshop on Geomagnetic Observatories and Survey Practice, PAIGH, 1984.

BARreto, L. M., Considerações sobre a variação secular e o modelamento do campo geomagnético no Brasil, Publicação No. 05/87, Observatório Nacional, 1987.

Chapman, S., Edmond Halley as a physical geographer and the story of his charts, R. Astron. Soc. Ocas. Notes, 2, 1941.

Chapman, S., Perspectives, in Physics of Geomagnetic Phenomena, Academic Press, 1967.

Gama, L. I., Recommendation of the South American Meeting on Geomagnetism, IAGA News, 8, 30-31, 1969a.

Gama, L. I., Campo magnético normal e sua variação secular no Brasil, Publicação No. 13/69, Observatório Nacional, $1969 \mathrm{~b}$.

Godor, R. C., Um modelo de declinação magnética e sua variação secular no Brasil nos últimos 70 anos, Observatório Nacional, 1970.

Haines, G. V., Spherical cap harmonic analysis, J. Geophys. Res., 90, 2583, 1985.

IAGA, Commission 2, Working Group No. 4, Analysis of the geomagnetic field, the International Geomagnetic Reference Field, J. Geomag. Geoelectr., 21, 569, 1969.

Langel, R. A., The main field, in Geomagnetism, edited by J. A. Jacobs, Vol. 1, Academic Press, 1987.

Motta, C. M. and L. M. Barreto, Campo geomagnético normal e sua variação secular no Brasil em 1985.0, Observatório Nacional, 1986.

Rodriguez, L., Informe Anual del IPGH, 1988, Secretaria General, Apartado Postal 18879, Mexico, DF, Mexico, 1990.

SchмidT, A., Ergebnisse der magnetischen Beobachtungen in Potsdam und Seddin den Jahren 1900-1910, Abhandl. Kge. Preuss. Met. Inst., 5, 1916.

WIEnert, K. A., Notes on Magnetic Observatory and Survey Practice, UNESCO, 1970. 